AperTO - Archivio Istituzionale Open Access dell'Università di Torino

Temporary implantable nitinol device (TIND): A novel, minimally invasive treatment for relief of lower urinary tract symptoms (LUTS) related to benign prostatic hyperplasia (BPH): Feasibility, safety and functional results at 1 year of follow-up

This is the author's manuscript

Original Citation:

Availability:

This version is available http://hdl.handle.net/2318/1623503

since 2017-01-28T17:00:37Z

Published version:

DOI:10.1111/bju.12982

Terms of use:

Open Access

Anyone can freely access the full text of works made available as "Open Access". Works made available under a Creative Commons license can be used according to the terms and conditions of said license. Use of all other works requires consent of the right holder (author or publisher) if not exempted from copyright protection by the applicable law. 
This is the author's final version of the contribution published as:

Porpiglia, Francesco; Fiori, Cristian; Bertolo, Riccardo; Garrou, Diletta; Cattaneo, Giovanni; Amparore, Daniele. Temporary implantable nitinol device (TIND): A novel, minimally invasive treatment for relief of lower urinary tract symptoms (LUTS) related to benign prostatic hyperplasia (BPH): Feasibility, safety and functional results at 1 year of follow-up. BJU INTERNATIONAL. 116 (2) pp: 278-287.

DOI: $10.1111 /$ bju. 12982

The publisher's version is available at: http://doi.wiley.com/10.1111/bju.12982

When citing, please refer to the published version.

Link to this full text:

http://hdl.handle.net/ 


\section{Temporary implantable nitinol device (TIND): a novel, minimally invasive treatment for relief of lower urinary tract symptoms (LUTS) related to benign prostatic hyperplasia (BPH): feasibility, safety and functional results at 1 year of follow-up}

Francesco Porpiglia, Cristian Fiori, Riccardo Bertolo, Diletta Garrou, Giovanni Cattaneo and Daniele Amparore

S.C.D.U. Urologia, Department of Oncology, School of Medicine, 'San Luigi Gonzaga' Hospital, University of Turin, Orbassano (Turin), Italy

\section{Abstract}

\section{Objectives}

To report the first clinical experience with a temporary implantable nitinol device (TIND; MediTate $^{\circledR}$ ) for the treatment of lower urinary tract symptoms (LUTS) due to benign prostatic hyperplasia $(\mathrm{BPH})$.

\section{Patients and Methods}

In all, 32 patients with LUTS were enrolled in this prospective study, which was approved by our Institutional Ethics Committee. Inclusion criteria were: age $>50$ years, International Prostate Symptom Score (IPSS) of $\geq 10$, maximum urinary flow rate $\left(\mathrm{Q}_{\max }\right)$ of $\leq 12 \mathrm{~mL} / \mathrm{s}$, and prostate volume of $<60 \mathrm{~mL}$. The TIND was implanted within the bladder neck and the prostatic urethra under light sedation, using a rigid cystoscope. The device was removed 5 days later in an outpatient setting. Demographics, perioperative results, complications (according to the Clavien system), functional results and quality of life (QoL) were evaluated. Follow-up assessments were made at 3 and 6 weeks, and 3, 6 and 12 months postoperatively. The Student's $t$-test, analysis of variance (anova), Kruskall-Wallis test, and simple and multiple linear regression models were used in the statistical analyses.

\section{Results}

The mean patient age was 69.4 years, the mean (standard deviation, sd) prostate volume was $29.5(7.4) \mathrm{mL}$ and the $\mathrm{Q}_{\max }$ was $7.6(2.2) \mathrm{mL} / \mathrm{s}$. The median (interquartile range, IQR) IPSS was 19 (14-23) and QoL score was 3 (3-4). All the implantations were successful, with no intraoperative complications recorded. The mean operative time (sd) was $5.8(2.5) \mathrm{min}$ and the median (IQR) postoperative stay was 1 (1-2) day. All but one of the devices (96\%) was removed 5 days at after implantation in an outpatient setting. Four complications (12.5\%) were recorded, including urinary retention (one, $3.1 \%$ ), transient incontinence due to device displacement (one, 
$3.1 \%$ ), prostatic abscess (one, $3.1 \%$ ), and urinary tract infection (one, 3.1\%). Multiple regression analysis failed to identify any independent prognostic factor for complications. There were statistically significant differences in the IPSS, QoL score and $\mathrm{Q}_{\max }$ when comparing pre- and postoperative results at every time point. After 12 months, the median (IQR) IPSS and QoL score were 9 (7-13) and 1 (1-2), respectively, and the mean (sd) $\mathrm{Q}_{\max }$ was 12 (4.7) $\mathrm{mL} / \mathrm{s}$. The mean variations with respect to baseline conditions at the same time points were $-45 \%$ for the IPSS and $+67 \%$ for $\mathrm{Q}_{\max }$. At 12 months after surgery (last follow-up visit), no patients required medical therapy or surgical procedures for $\mathrm{BPH}$.

\section{Conclusion}

TIND implantation is a feasible and safe minimally invasive option for the treatment of BPHrelated LUTS. The functional results are encouraging and the treatment significantly improved patient QoL. Further studies are required to assess durability of TIND results and to optimise the indications of such a procedure.

\section{Introduction}

Moderate-to-severe LUTS resulting from BPH affect $\approx 30 \%$ of men aged $>50$ years, including 26 million men in Europe and 8 million in the USA [1]. Medical therapy ( $\alpha$-blockers and $5 \alpha-$ reductase inhibitors) is often the first therapeutic option for these patients, even if it provides only modest symptomatic relief, as assessed by improvements in the IPSS [1,2]. Due to the incidence of side-effects, together with inadequate symptoms relief, $>25 \%$ of patients on drug therapy discontinue treatment; some of these patients opt for surgical intervention $[1,2]$.

TURP remains the 'gold standard' in the surgical treatment of BPH, and has documented decreased IPSS and increased maximum urinary flow rate $\left(\mathrm{Q}_{\max }\right)$ by up to $70 \%$ and $149 \%$, respectively [3-6]. The main disadvantages of TURP include perioperative morbidity and long-term complications, such as postoperative bleeding, urinary retention, incontinence, urethral strictures and sexual dysfunction (up to $65 \%$ of patients if retrograde ejaculation is considered) [6]. The newer, extremely attractive laser-based methods of treatment such as holmium laser enucleation of the prostate, thulium laser enucleation of the prostate, and photovaporisation of the prostate, are still associated with complication rates comparable with those of TURP [7, 8].

Considering these findings, there is still a considerable proportion of men who seek more significant symptomatic improvement than is offered by medicinal therapy but who are not willing to subject themselves to the risks associated with surgery. Thus, different minimally invasive procedures have been introduced with the aim of reducing the morbidity of TURP, such as transurethral needle ablation (TUNA), transurethral microwave thermotherapy (TUMT), and transurethral ethanol ablation of prostate (TEAP). However, their position in the management of BPH is still controversial $[5,7]$. More recently, a step in this direction was made: some reports presented data about a new procedure called prostate urethral lift (PUL) [9, 10].

In the present study, we report the first clinical experience with a temporary implantable nitinol device (TIND; Medi-Tate ${ }^{\circledR}$; Medi-Tate Ltd., Or Akiva, Israel), a new device developed to provide a minimally invasive means of increasing prostatic urethral patency to relieve the symptoms of urinary outflow obstruction secondary to BPH. The TIND is crimped and delivered through a cystoscope sheath, and then, when placed in the urethra, it is released from the cystoscope sheath to assume its expanded configuration, thereby reshaping the urethra and the bladder neck. The purpose of the present study was to determine the feasibility and safety of the TIND procedure in patients with LUTS due to BPH. 


\section{Patients and Methods}

\section{Study Design}

In this single-arm, prospective study, we evaluated the feasibility and the safety of TIND implantation in patients presenting with LUTS secondary to BPH. After the approval of the Local Institutional Ethic Committee, the study was conducted at the Division of Urology, San Luigi Gonzaga Hospital, University of Turin, Orbassano (Turin), Italy and the enrolment phase lasted from May 2010 to July 2013. All patients were accurately informed about the procedure and signed a detailed consent form.

\section{Inclusion Criteria}

Age $>50$ years, IPSS of $\geq 10, Q_{\max }$ of $\leq 12 \mathrm{~mL} / \mathrm{s}$, prostate volume assessed by TRUS of $<60 \mathrm{~mL}$.

\section{Exclusion Criteria}

Previous prostate surgery, prostate cancer, urethral stricture, bladder stones, obstructing median lobe. Patients were also excluded if they had a history of significant medical co-morbidity, haemostatic disorder or suspected neurological conditions that could potentially affect voiding function.

\section{TIND and Surgical Equipment}

The TIND is comprised of elongated struts and an anchoring leaflet all made of nitinol, a biocompatible super elastic shape-memory alloy widely used in the manufacture of medical devices (Fig. 1). The total length of the device is $50 \mathrm{~mm}$ and its outer diameter is $33 \mathrm{~mm}$, designed to cover the entire length of the prostatic urethra, from the bladder neck to a point proximal to the external urinary sphincter.

\section{Figure 1.}

- Open in figure viewer 
- Download Powerpoint slide

The Medi-tate TIND in its expanded configuration. (a) Longitudinal view. Note the nitinol struts and the anchoring leaflet (*). The total length of the device is $50 \mathrm{~mm}$. The tip of the device is covered (soft plastic material) to avoid any bladder injury. (b) Front view. The width of the device is $33 \mathrm{~mm}$, the struts are designed to create prostate incisions anteriorly, at the 5 and 7 o'clock positions. The anchoring leaflet is marked with*.

When in its expanded configuration, the struts of the TIND exert radial force outwardly on the bladder neck and the prostatic urethra, to push obstructive tissue away from the urinary path. The TIND is left in position for 5 days. The device is subsequently removed using a cystoscope sheath under visualisation. The device is delivered and removed through a standard $22 \mathrm{~F}$ cystoscope (Storz, Tuttlingen, Germany) with a 5 -mm $30^{\circ}$ optic.

\section{Mechanism of Action}

The radial force exerted by the struts cause ischaemic necrosis of the tissue, leading to bladder neck and prostatic urethra incision. The hypothesis is that these incisions 'reshape' the prostatic urethra and the bladder neck and reduce the urinary flow obstruction caused by the prostatic tissue.

\section{Surgical Procedure}

1. TIND implantation. The procedure is performed under light i.v. sedation. In addition, as antibiotic prophylaxis, a single i.v. dose $(500 \mathrm{mg})$ of levofloxacin is administered. The patient is placed in a lithotomy position. The cystoscope is gently inserted in to the urethral meatus, and a standard urethro-cystoscopy is performed. The TIND, preloaded on a dedicated delivery system, is advanced into the bladder through the cystoscope sheath, and deployed inside the bladder. The device is then further manipulated under direct visualisation, until the anchoring leaflet slides to its position at 6 o'clock distal to the bladder neck and the device is securely positioned within the bladder neck and the prostatic urethra (Figs 2 and 3). Finally, the bladder is emptied and the cystoscope is removed. No catheterisation is required.

\section{Figure 2.}

- Open in figure viewer

- Download Powerpoint slide 
(a) The device, preloaded on a dedicated delivery system, is advanced into the bladder through the cystoscope sheath, and deployed inside the bladder. (b) The device rotated by using the delivery system until the anchoring leaflet $(*)$ reaches the 6 o'clock position. To facilitate this step, the bladder is filled with saline solution.

\section{Figure 3.}

- Open in figure viewer

- Download Powerpoint slide

Once the device is correctly oriented, it is gently retracted into the prostatic urethra, until the anchoring leaflet $(*)$ slides to its position, between the bladder neck and the verumontanum. This step of the procedure is performed under direct vision and the surgeon has the tactile feedback of the correct positioning of the device. By this way the device is secured within the bladder neck and prostatic urethra. - , bladder neck.

2. TIND removal. At 5 days after placement, the TIND is retrieved in an outpatient setting. The patient is placed in a lithotomy position and $20 \mathrm{~mL}$ lidocaine gel is applied to the urethral meatus. Urethroscopy is performed with a standard 22-F cystoscope, and the TIND is identified (Fig. 4), retracted into the cystoscope sheath under visualisation, and then removed. 


\section{Figure 4.}

- Open in figure viewer

- Download Powerpoint slide

Endoscopic vision just before TIND removal. Note that anchoring leaflet (*) in its correct position, and the incision done by the device anteriorly, at 5 and 7 o'clock positions (-).

\section{Post-Implantation Care}

Patients were monitored after surgery as per protocols for a standard endoscopic procedure. Paracetamol (1 $000 \mathrm{mg}$ ) was administered i.v. after surgery per local protocol, and then if required by the patients. Subjective pain levels were scored using a visual analogue scale (VAS).

\section{Follow Up Visits}

Patients were visited at 5 days (removal day), 3 and 6 weeks, and 3, 6, and 12 months after the implantation. Follow-up visits included uroflowmetry, IPSS and IPSS quality-of-life (QoL) assessments.

To assess patient satisfaction with the surgical intervention, question 32 of the Expanded Prostate Cancer Index Composite (EPIC) questionnaire [11, 12] was posed during the follow-up visits: 'Overall, how satisfied are you with treatment you received for your prostate disease intervention?' (1: extremely dissatisfied; 2 : dissatisfied; 3 : uncertain; 4; satisfied; 5: extremely satisfied).

Adverse events during the follow-up period were recorded. For the purpose of this study, complications were defined as 'early' when they occurred $\leq 30$ days of surgery and 'late' if they occurred $>30$ days after surgery. Early complications were classified according to the Clavien system [12].

\section{Study Endpoints}


The primary endpoint of the study was to evaluate the feasibility and safety of the procedure; the secondary endpoint was to evaluate the functional results of the procedure based on the IPSS and uroflowmetry.

\section{Statistical Analysis}

Data were expressed as means and standard deviations (sds) for continuous variables, and as frequencies and proportion or median and interquartile ranges (IQRs) for categorical variables. The means of continuous variables were compared by using the Student's $t$-test after verifying that the variables to be analysed were approximately normally distributed. anova was used to compare the means of more than two groups, whilst statistical comparisons among different subgroups were performed by using the Kruskall-Wallis test for categorical variables.

Simple and multiple linear regression models were built to identify any independent factors for overall complications, improvement of $\mathrm{Q}_{\max }$ and decrease in the IPSS at 12 months after surgery. Clinical characteristics including age, American Society of Anesthesiologists (ASA) score, body mass index (BMI), prostate size, $\mathrm{Q}_{\max }$ and the IPSS at baseline, and surgeon were used in the regression models. A $P<0.05$ was considered to indicate statistical significance. Statsoft (Tulsa, OK, USA) Version 8.0 for Windows was used for statistical analysis.

\section{Results}

\section{Patient Demographics}

In all, 32 patients underwent TIND implantation; their demographic and baseline characteristics are summarised in Table 1.

Table 1. Baseline characteristics of the patients

Characteristic

1. ECOG, Eastern Cooperative Oncology Group (performance status); 5-ARI, $5 \alpha$-reductase inhibitor.

Number of patients

Mean (sd)

Age, years

BMI, kg/m²

PSA level, ng/mL

Prostate volume, $\mathrm{mL}$

$\mathrm{Q}_{\max }, \mathrm{mL} / \mathrm{s}$

Preoperative haemoglobin levels, g/dL

Median (IQR)

ASA score

ECOG score

$0(0-1)$

Preoperative IPSS

$19(14-23)$

Preoperative IPSS QoL index

$3(3-4)$

Charlson comorbidity index

$1(0-2)$

$N(\%)$ 
Characteristic

Patients with bladder catheter before the intervention

$\alpha$-blocker therapy

$\alpha$-blocker + 5-ARI therapy (\%)
Value

0

$32(100)$

$15(46)$

\section{Perioperative Results}

All patients were treated with light sedation, and all the implantations were successful. No intraoperative complications were recorded. The mean (sd) operative time, from introduction of the TIND system until withdrawal of the delivery system, was 5.8 (2.5) min.

The median (IQR) VAS score at $6 \mathrm{~h}$ after the procedure was $2(2-4)$, while the median paracetamol use during this period was one $1000 \mathrm{mg}$ vial per patient. The median (IQR) duration of the postoperative stay was 1 (1-2) days. From the 20th procedure, patients were discharged on the same day as the surgery. None of the patients was readmitted before device removal. All but one of the devices was removed 5 days after implantation, in an outpatient setting. The mean (sd) operative time was 2 (1) min, and all procedures were uneventful.

\section{Complications}

Overall, four patients (12.5\%) presented complications that are summarised in Table 2. One patient $(3.1 \%)$ reported urinary incontinence 1 day after surgery, so the device was immediately removed. During the cystoscopy, the distal portion of the wires was identified distal to the sphincter, suggesting displacement of the device. After TIND removal, the patient reported no urine leakage. One patient $(3.1 \%)$ had urinary retention the same day of the implantation. In this case, the bladder was voided by using a small $(10 \mathrm{~F})$ Tieman catheter, which was immediately removed. Thereafter, the patient was able to urinate spontaneously. Two patients $(6.2 \%)$ developed infections. In the first case, a UTI was diagnosed 2 weeks after the implantation and was successfully treated by antibiotic therapy. The second patient (affected with type II diabetes) presented fever $\left(38^{\circ} \mathrm{C}\right)$ with urinary symptoms, atrial fibrillation and uncontrolled glucose levels (>400 mg/dL) 4 weeks after implantation. He was readmitted, blood tests and TRUS were performed with a diagnosis of a $2-\mathrm{cm}$ prostatic abscess. The patient was successfully treated with medical therapy, with no sequelae after discharge (Table 2). No late complications were recorded. Furthermore, no patients required adjunctive surgical treatments during the follow-up period. When comparing the subgroup of patients who had postoperative complications (four patients) with the subgroup of patients who did not (28), there were no differences in age, BMI, preoperative PSA levels, IPSS, co-morbidities, ASA score, prostate volume or operative time. Multiple regression analysis failed to identify any independent prognostic factors for complications.

Table 2. Complications after TIND implantation

\section{Patient Demographic \\ ID data Complication Grade* Early/late \\ Management \\ Sequelae}

1. AF, atrial fibrillation; *According to Clavien system.

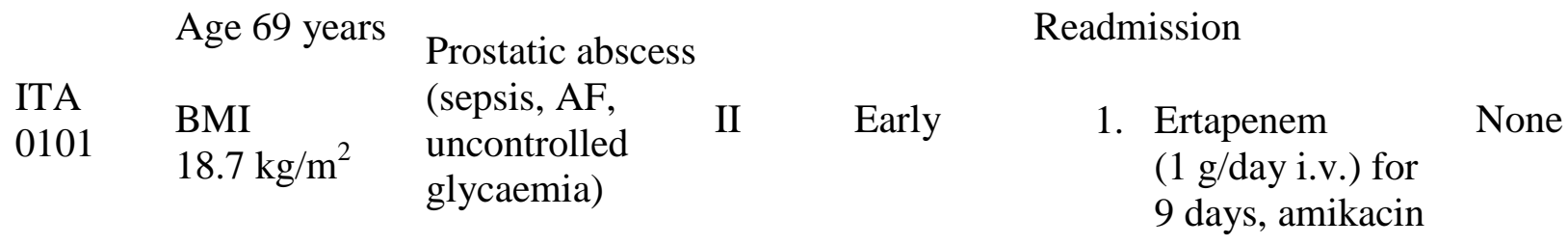




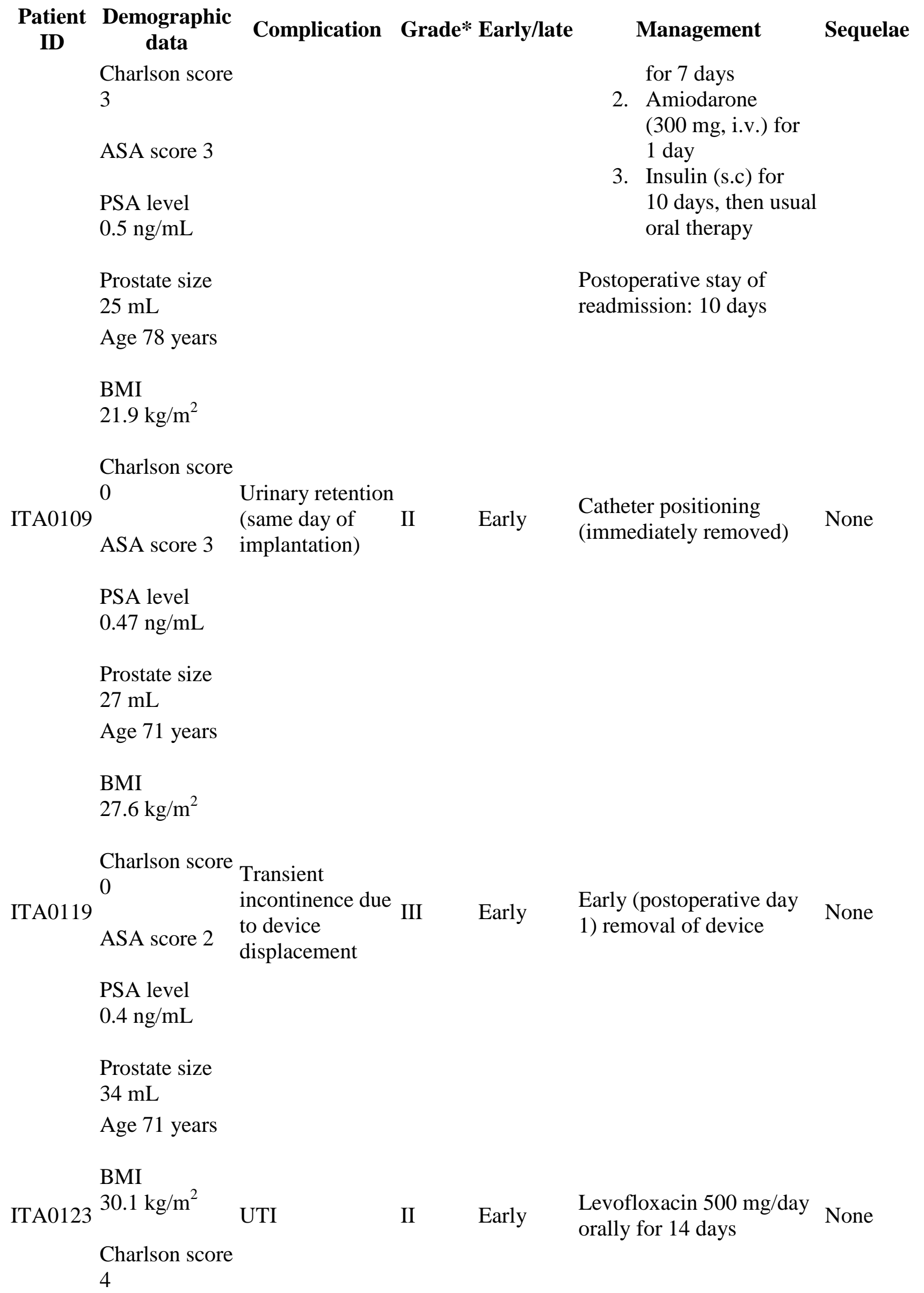




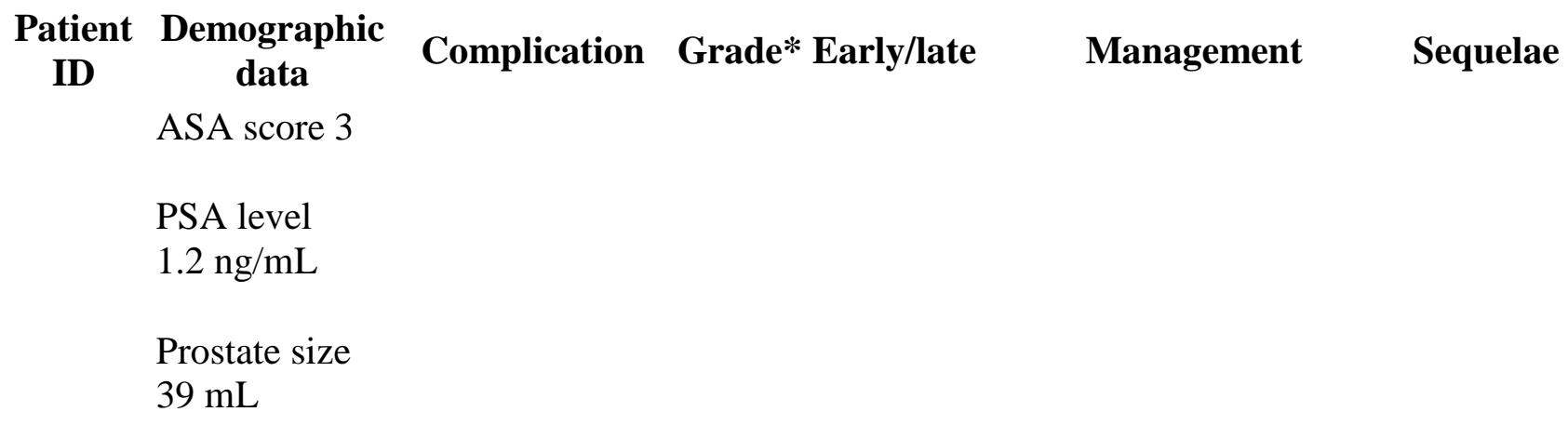

\section{Functional Results}

$\mathrm{Q}_{\max }$ values, the IPSS and IPSS QoL index results measured at the baseline and at scheduled time points during the follow-up period are reported in Figs 5 and 6. Figures 7 and 8 show the percentage changes in $\mathrm{Q}_{\max }$ and the IPSS at the different time points with respect to baseline. There were no differences in the IPSS and IPSS QoL index among the different time points during the follow-up, on the contrary, there were statistically significant variations in $\mathrm{Q}_{\max }$ during the follow-up (Table 3). All patients discontinued medical therapy at 3 months after surgery. Multiple regression analysis did not identify any independent prognostic factor predictive of higher improvement of the IPSS and $\mathrm{Q}_{\max }$. At 12 months after surgery (last follow-up visit), no patients required medical therapy or surgical procedures for BPH. For the EPIC score (Fig. 6 and Table 3) at 12 months after surgery, 26 patients $(82 \%)$ were 'satisfied' or 'extremely satisfied' with the intervention, five (15\%) patients were uncertain about their satisfaction and only one (3\%) patient was 'dissatisfied'.

Table 3. Functional results and overall satisfaction of patients with TIND procedures evaluated during the follow-up

\section{3 weeks 6 weeks 3 months 6 months 12 months $P$}

1. $a$

'Overall, how satisfied are you with treatment you received for your prostate disease intervention?' (1: extremely dissatisfied; 2 : dissatisfied; 3: uncertain; 4; satisfied; 5: extremely satisfied).

\begin{tabular}{|c|c|c|c|c|c|c|}
\hline Mean (sd) $\mathrm{Q}_{\max }, \mathrm{mL} / \mathrm{s}$ & $10.0(4.4)$ & $12.5(4.1)$ & $11.7(4.7)$ & $11.4(4.2)$ & $11.9(4.7)$ & $<0.01$ \\
\hline Median (IQR) & & & & & & \\
\hline IPSS & $10(8-11)$ & $8(7-10)$ & $8(6-10)$ & $9(7-12)$ & $9(7-13)$ & 0.18 \\
\hline IPSS QoL index & $2(1-2)$ & $1(1-2)$ & $1(1-2)$ & $1(1-2)$ & $1(1-2)$ & 0.45 \\
\hline $\begin{array}{l}\text { EPIC index question } \\
32 \mathrm{a}\end{array}$ & $5(4-5)$ & $5(4-5)$ & $5(4-5)$ & $5(4-5)$ & $5(4-5)$ & 1 \\
\hline
\end{tabular}




\section{Figure 5.}

- Open in figure viewer

- Download Powerpoint slide

$\mathrm{Q}_{\max }$ evaluated pre- and postoperatively. The differences between the pre- and postoperative values at every time point were statistical significant. pre., preoperative; w., weeks; mo., months.

\section{Figure 6.}

- Open in figure viewer

- Download Powerpoint slide

The IPSS, IPSS QoL score and EPIC score evaluated pre- and postoperatively. The differences between the pre- and postoperative values at every time point were statistical significant for all the considered variables. p.o., postoperatively. 


\section{Figure 7.}

- Open in figure viewer

- Download Powerpoint slide

Changes in $\mathrm{Q}_{\max }$ at the different time points with respect to baseline values. IQmax, increase in $\mathrm{Q}_{\max }$; w., weeks; mo., months.

\section{Figure 8.}

- Open in figure viewer

- Download Powerpoint slide

Changes in the IPSS at the different time points with respect to baseline values. DIPSS, decrease in IPSS; w., weeks; mo., months. 


\section{Discussion}

Many men with LUTS due to BPH are dissatisfied with current medical treatment options but do not accept TURP or more recent laser-based therapies as an option, mainly due to subsequent sexual dysfunction, perioperative urinary urgency/frequency symptoms or risks of complications. In addition, some Authors have reported that LUTS have a lower impact on QoL than sexual dysfunction or incontinence [1,13-15]. To reduce the invasiveness of TURP, many minimally invasive surgical options have been proposed during recent decades (Table 4) [16-24].

Table 4. Results of minimally invasive techniques for the treatment of LUTS due to BPH

$\begin{array}{cccccc}\text { References } & \text { Procedure } & \begin{array}{c}\text { Follow- } \\ \text { up, } \\ \text { weeks }\end{array} & \begin{array}{c}\text { Patients, } \\ n\end{array} & \begin{array}{c}\text { Estimated } \\ \text { change in } \\ \text { IPSS, \% }\end{array} & \begin{array}{c}\text { Estimated } \\ \text { change in } \\ \mathbf{Q}_{\max } \%\end{array}\end{array}$ Main complications

Three study arms comparing transurethral, transrectal and transperineal injections; NA, not available.

$\begin{array}{lcccccc}\begin{array}{l}\text { Hoffman } \\ \text { et al. [18] }\end{array} & \text { TUMT } & 52 & 322 & -65 & 70 & \text { NA } \\ \begin{array}{l}\text { Trock et al. } \\ \text { [21] }\end{array} & \text { TUMT } & 208 & 541 & -42.7 & 35 & \text { NA } \\ \text { Guazzoni } & & & & & & \end{array}$

$\begin{array}{lllllll}\begin{array}{l}\text { Guazzoni } \\ \text { et al. [16] }\end{array} & \text { Urolume } & 18 & 91 & -66.6 & 83.8 & \begin{array}{l}\text { Long-term complications } \\ 38 \%\end{array}\end{array}$

Early postoperative

Haematuria 51.2\%;

dislocation $8.9 \%$

Gesenberg

3-12 months

and

Sintermann

Memotherm 104

$123-74.5$

125.6

[22]

Perry et al.

[23]

Memokath 336

$211 \quad-59.6$

NA

postoperative

UTI 45.5\%; urothelial hyperplasia $27.6 \%$, dislocation $1.6 \%$, explantation $4.1 \%$, ureteric stricture $10.6 \%$, stone formation $3.2 \%$

Migration 13\%; urinary retention $10 \%$, incontinence $6 \%$; UTI $6 \%$, stone formation $2 \%$ Urinary retention $17 \%$, haematuria $16 \%$, UTI

Grise et al. [19] $\begin{array}{llll}\text { TEAP } & 52 & 115 & -50\end{array}$ $8 \%$, incontinence $4 \%$, erectile dysfunction $3 \%$, ejaculatory dysfunction $1 \%$

Plante et al. [20]

TEAP $\quad 24 \quad 79 \quad-47$ to -55 a $37-94 a$

Irritative voiding symptoms $40.3 \%$, urinary 


\begin{tabular}{|c|c|c|c|c|c|c|}
\hline References & Procedure & $\begin{array}{c}\text { Follow- } \\
\text { up, } \\
\text { weeks }\end{array}$ & $\begin{array}{c}\text { Patients, } \\
n\end{array}$ & $\begin{array}{l}\text { Estimated } \\
\text { change in } \\
\text { IPSS, \% }\end{array}$ & $\begin{array}{c}\text { Estimated } \\
\text { change in } \\
\mathbf{Q}_{\max } \%\end{array}$ & $\begin{array}{l}\text { Main complications } \\
\text { retention } 22.1 \% \text {, UTI } \\
10.1 \% \text {; erectile } \\
\text { dysfunction } 3.7 \% \text {, } \\
\text { ejaculatory dysfunction } \\
3.7 \%\end{array}$ \\
\hline $\begin{array}{l}\text { Hill et al. } \\
\text { [17] }\end{array}$ & TUNA & 52 & 56 & -51.2 & NA & $\begin{array}{l}\text { Erectile dysfunction } 3 \% \text {, } \\
\text { urinary incontinence } 2 \% \text {; } \\
\text { re-intervention } 13.8 \%\end{array}$ \\
\hline $\begin{array}{l}\text { Zlotta et al. } \\
\text { [24] }\end{array}$ & TUNA & 52 & 131 & -58.3 & 40.6 & NA \\
\hline
\end{tabular}

The 'prostatic' stent was primarily designed as an alternative to an indwelling catheter in patients unfit for surgery but it has also been indicated as a primary treatment option in patients without significant co-morbidities $[16,25]$. Because of the side-effects and the high migration rate, prostatic stents have a limited role in BPH treatment [5]. Heating therapies with microwaves and radiofrequencies (TUMT and TUNA) may have fewer complications than TURP $[17,18]$. However, it is known they might have unpredictable results and require up to 2 months of worsened symptoms before a significant improvement of $Q_{\max }$ and the IPSS [5, 26].

The minimally invasive TEAP option is scarcely covered in the Literature and its mechanism of action has not been well investigated. In addition, the technique has not been standardised and finally, severe adverse events have been reported [19]. For these reasons, TEAP is still considered experimental and should be used only in trials $[5,20]$. More recently, the PUL procedure has been proposed as a novel, minimally invasive technique to improve LUTS due to BPH $[9,10]$. In the PUL procedure, the lateral lobes of the prostate are displaced by small suture-based implants towards the capsule with the aim of expanding the urethral lumen [9, 10, 27]. In the first clinical experience with 19 patients, at 1 year after PUL the mean IPSS decreased by $39 \%$ compared with the baseline value [9]. However, non-significant increases in $\mathrm{Q}_{\max }$ at the different time points were reported. In a recent multinational experience, the IPSS, IPSS QoL score and $\mathrm{Q}_{\max }$ significantly improved 1 year after the procedure, yet $6.5 \%$ of the patients progressed to TURP within 1 year [10].

TIND was developed in an effort to create an efficient and minimally invasive technique for treating the symptoms of urinary outflow obstruction secondary to BPH. In the present study, we report the first clinical experience with TIND and show that the implantation of this device is feasible and safe in the treatment of BPH-related symptoms. All the procedures were successfully completed, performed under light sedation, and required only a few minutes to perform. Neither intraoperative complications nor technical difficulties were recorded. From a technical point of view, the procedure was simple and did not require any special equipment. The key point is the correct placement of the device; after filling of the bladder with saline solution, the device must be delivered into the bladder and rotated until the anchoring leaflet is placed at the 6 o'clock position at the bladder neck. Once this orientation is correct, the device is gently retracted until the anchoring leaflet slides distal to the bladder neck. Unlike other minimally invasive procedures, the surgeon has direct visualisation of the device throughout the procedure. Moreover, at his discretion, the surgeon can easily relocate and even withdraw the device even after it has been deployed. During the postoperative period, paracetamol (1 $000 \mathrm{mg}$, i.v.) was administered to all patients, per local protocol, and no patients required adjunctive analgesic drugs, suggesting that overall the procedure 
was well tolerated. All but one patient was able to void the same day of surgery, with no need of postoperative catheterisation. This is one of the most positive aspects of the procedure. The duration of hospital stay was longer for the first patients, who were more strictly monitored during the postoperative period, as it is standard when implementing new techniques. However, after the initial encouraging results, all patients were discharged on the same day of the surgery.

Theoretically, one of the major concerns of this procedure was the tolerability of the device once implanted. After the discharge and before the TIND removal (at day 5), we recorded neither unplanned visits nor readmissions, suggesting that the device was well tolerated by all the patients.

Removal of the device was performed without any complications in all cases. All patients were able to void immediately after device removal, confirming the feasibility of this manoeuvre in an ambulatory setting.

Overall, there were four 'early' complications (Table 2). Of note, one patient reported urinary incontinence due to device displacement, but after removal, the patient was completely continent. In one patient, prostatic abscess complicated by sepsis, atrial fibrillation and uncontrolled glycaemia was recorded 4 weeks after implantation. The patient was readmitted and pharmacologically treated with no sequelae after discharge. Regression models failed to identify any independent prognostic factors for complications, despite the fact that both infections were recorded in patients with ASA 3 and a Charlson comorbidity index higher than the median value. After implantation, no complications occurred in the studied population during the first 30 days, demonstrating the safety of the procedure. For functional results, significant improvements in the postoperative IPSS and $\mathrm{Q}_{\max }$ compared with baseline were recorded. Notably, this improvement was recorded early, within 3 weeks of the procedure, presenting an important positive aspect of this procedure, as the vast majority of other minimally invasive techniques can require several weeks before improvement [5, 19]. Moreover, the IPSS remained stable during the entire follow-up period. Slight but statistically significant changes were observed in $\mathrm{Q}_{\max }$ measured at the different time points during the followup (Table 3), even if probably not clinically relevant. After 1 year, the mean improvement of the IPSS and $\mathrm{Q}_{\max }$ was $45 \%$ and $67 \%$, respectively. Notably, all patients discontinued medical therapy 3 months after surgery. These results are at least comparable, if not superior, to those of other minimally invasive procedures, even the most novel ones [7, 28]. The QoL scores followed the same trend as the IPSS, with patients reporting a significant improvement in QoL, which remained stable at the different follow-up time points throughout the study (Table 3). These data suggested that TIND implantation positively affected the QoL of the patients, a key factor when assessing a new surgical strategy for BPH treatment. The results of EPIC question 32 further confirmed that the procedure was well accepted by the patients. Finally, no patients required more invasive treatments (i.e., TURP) during the follow-up period, further demonstrating the efficacy (at least measured in a short follow-up period) of the procedure. We consider this result noteworthy when compared with other techniques $[10,29,30]$.

The present study was not devoid of limitations. Firstly, the sample size was small. Secondly, the duration of follow-up was somewhat short. Nevertheless, one must note that the main endpoint of our present study was to demonstrate the feasibility and safety of the procedure, and we think that the presented data are sufficient in demonstrating these points. Thirdly, prostate size was small and treatment results for larger prostates are lacking.

Notwithstanding the abovementioned limitations, we can conclude that TIND implantation is a feasible and safe minimally invasive option for the treatment of BPH-related LUTS, as evidenced by the excellent perioperative results and the low complication rate. The procedure is simple, fast (a few minutes) and does not require any special equipment. The functional results are encouraging 
and the treatment significantly improved the patient's QoL. Further studies are required to assess the long-term durability of TIND results and to better define the indications of such a procedure.

\section{Conflict of Interest}

The authors declare that they have no conflicts of interest.

Abbreviations

ASA

American Society of Anesthesiologists

BMI

body mass index

EPIC

Expanded Prostate Cancer Index Composite (questionnaire)

IQR

interquartile range

PUL

prostate urethral lift

$\mathrm{Q}_{\max }$

maximum urinary flow rate

QoL

quality of life

TEAP

transurethral ethanol ablation of prostate

TIND

temporary implantable nitinol device

TUMT

transurethral microwave thermotherapy

TUNA 
transurethral needle ablation

VAS

visual analogue scale

- Roehrborn CG. Current medical therapies for men with lower urinary tract symptoms and benign prostatic hyperplasia: achievement and limitations. Rev Urol 2008; 10: 14-25

- 2 Verhamme KM, Dieleman JP, Bleumink GS, Bosch JL, Stricker BH, Sturkenboom MC. Treatment strategies, patterns of drug use and treatment discontinuation in men with LUTS suggestive of benign prostatic hyperplasia: the Triumph Project. Eur Urol 2003; 44: 539-45

- 3Marszalek M, Ponholzer A, Pusman M, Berger I, Madersbacher S. Transurethral resection of the prostate. Eur Urol Suppl 2009; 8: 504-12

- 4Geavlete P. Is classical transurethral resection of the prostate, the gold standard endoscopic treatment for benign prostate hyperplasia, in real danger of being replaced? Eur Urol 2010; 58: $356-9$

- 5Oelke M, Bachmann A, Descazeaud A et al. EAU Guidelines on the treatment and follow-up of non-neurogenic male lower urinary tract symptoms including benign prostatic obstruction. Eur Urol 2013; 64: 118-40

- 6Madersbacher S, Marberger M. Is transurethral resection of the prostate still justified? BJU Int 1999; 83: 227-37

- 7Lourenco T, Pickard R, Vale L et al. Minimally invasive treatments for benign prostatic enlargement: systematic review of randomised controlled trials. BMJ 2008; 337: al662

- 8Gravas S, Bachmann A, Reich O, Roehrborn CG, Gilling PJ, De La Rosette J. Critical review of lasers in benign prostatic hyperplasia (BPH). BJU Int 2011; 107: 1030-43

- 9Woo HH, Chin PT, McNicholas TA et al. Safety and feasibility of the prostatic urethral lift: a novel, minimally invasive treatment for lower urinary tract symptoms (LUTS) secondary to benign prostatic hyperplasia (BPH). BJU Int 2011; 108: 82-8

- 10McNicholas TA, Woo HH, Chin PT, Bolton D, Arjona MF, Sievert KD. Minimally invasive prostatic urethral lift: surgical technique and multinational experience. Eur Urol 2013; 64: 292-9

- 11 Wei JT, Dunn RL, Litwin MS, Sandler HM, Sanda MG. Development and validation of the expanded prostate cancer index composite (EPIC) for comprehensive assessment of health-related quality of life in men with prostate cancer. Urology 2000; 56: 899-905

- 12Dindo D, Demartines N, Clavien PA. Classification of surgical complications: a new proposal with evaluation in a cohort of 6336 patients and results of a survey. Ann Surg 2004; 240: 205-13 
- 13 Valtbakk J, Hanestad BRT, Hunskaar S. Relevance and variability of the severity of incontinence and increased daytime and night-time voiding frequency, associated with quality of life in men with lower urinary tract symptoms. BJU Int 2005; 96: 83-7

- 14Haltbakk J, Hanestad BR, Hunskaar S. How important are men's lower urinary tract symptoms (LUTS) and their impact on the quality of life (QOL)? Qual Life Res 2005; 14: 1733-41

- 15Patel VR, Sivaraman A, Coelho RF et al. Pentafecta: a new concept for reporting outcomes of robot-assisted laparoscopic radical prostatectomy. Eur Urol 2011; 59: 702-7

- 16Guazzoni G, Montorsi F, Coulange C et al. A modified prostatic UroLume Wallstent for healthy patients with symptomatic benign prostatic hyperplasia: a European Multicenter Study. Urology 1994; 44: 364-70

- 17Hill B, Belville W, Bruskewitz R et al. Transurethral needle ablation versus transurethral resection of the prostate for the treatment of symptomatic benign prostatic hyperplasia: 5-year results of a prospective, randomized, multicenter clinical trial. J Urol 2004; 171: 2336-40

- 18Hoffman RM, Monga M, Elliot SP, Macdonald R, Wilt TJ. Microwave thermotherapy for benign prostatic hyperplasia. Cochrane Database Syst Rev 2007;4:CD004135. Review. Update in: Cochrane Database Syst Rev. 2012; (9): CD004135

- 19Grise P, Plante M, Palmer J et al. Evaluation of the transurethral ethanol ablation of the prostate (TEAP) for symptomatic benign prostatic hyperplasia (BPH): a European multi-center evaluation. Eur Urol 2004; 46: 496-501

- 20Plante MK, Marks LS, Anderson R et al. Phase I/II examination of transurethral ethanol ablation of the prostate for the treatment of symptomatic benign prostatic hyperplasia. J Urol 2007; 177: $1030-5$

- 21Trock BJ, Brotzman M, Utz WJ et al. Long-term pooled analysis of multicenter studies of cooled thermotherapy for benign prostatic hyperplasia results at three months through four years. Urology 2004; 63: 716-21

- 22Gesenberg A, Sintermann R. Management of benign prostatic obstruction in high risk patients: longterm experience with the Memotherm stent. J Urol 1998; 160: 72-6

- 23Perry MJ, Roodhouse AJ, Gidlow AB et al. Thermo-expandable intraprostatic stents in bladder outlet obstruction: an 8-year study. BJU Int 2002;90:216-23.

- 24Zlotta AR, Giannakopoulos X, Maehlum O et al. Long-term evaluation of transurethral needle ablation of the prostate (TUNA) for treatment of symptomatic benign prostatic hyperplasia: clinical outcome up to five years from three centers. Eur Urol 2003; 44: 89-93

- 25Vanderbrink BA, Rastinehad AR, Badlani GH. Prostatic stents for the treatment of benign prostatic hyperplasia. Curr Opin Urol 2007; 17: 1-6

- 26Schatzl G, Madersbacher S, Lang T, Marberger M. The early postoperative morbidity of transurethral resection of the prostate and of four minimally invasive treatment alternatives. J Urol 1997; 158: 105-11 
- 27Cantwell AL, Bogache WK, Richardson SF et al. Multicentre prospective crossover study of the 'prostatic urethral lift' for the treatment of lower urinary tract symptoms secondary to benign prostatic hyperplasia. BJU Int 2014; 113: 615-22

- 28Blute ML, Larson T. Minimally invasive therapies for benign prostatic hyperplasia. Urology 2001; 58(Suppl. 1): 33-41

- 29Goya N, Ishikawa N, Ito F et al. Transurethral ethanol injection therapy for prostatic hyperplasia: 3-year results. J Urol 2004; 172: 1017-20

- 30Brisinda G, Cadeddu F, Vanella S et al. Relief by botulinum toxin of lower urinary tract symptoms owing to benign prostatic hyperplasia: earl and long-term results. Urology 2009; 73: $90-4$ 